\title{
Effect of Abscisic Acid in the Avena Curvature Test
}

\author{
by Tohru HASHIMOTo* and Saburo TAMURA*
}

\author{
Received September 11, 1968
}

\begin{abstract}
d-Abscisic acid (ABA) does not affect the indole-3-acetic acid (IAA)-induced curvature in the standard Avena coleoptile test at a dosage level of IAA which gives a linear doseresponse curve, while ABA is inhibitory in the neighborhood of the saturation dosage of IAA. Consequently the need to remove ABA from samples to be subjected to this test for the estimation of auxins is eliminated.
\end{abstract}

d-Abscisic acid (ABA) is known to inhibit effectively the straight growth of Avena coleoptile sections induced by indole-3-acetic acid (IAA) ${ }^{1,2}$. However, its effect on the Avena curvature test has not been investigated.

ABA occurs widely in plants ${ }^{3-7)}$ and has been shown to be transported basipetally through stem or petiole sections ${ }^{8)}$. Therefore, it is probable that acidic ether extract from plant tissues, and diffusates ${ }^{9,10)}$ collected in agar blocks from the cut surfaces of stems or petioles may contain ABA in addition to auxins. Thus, it may make questionable the validity of the Avena curvature method to estimate auxins in plant tissues. In this connection the present paper deals with the effect of ABA on the Avena curvature test.

Avena curvature test was performed with Avena sativa, cv. Victory according to Went's standard method ${ }^{9}$. Agar blocks, $2 \times 2 \times 2 \mathrm{~mm}$, contained IAA, ABA or both in varied concentrations. The ABA concentrations applied here are high enough to inhibit completely the elongation of Avena coleoptile sections induced by 0.1 and 1 $\mu \mathrm{g} / \mathrm{m} l$ of IAA. Curvature was measured $90 \mathrm{~min}$ after the placing of agar blocks.

$\mathrm{ABA}$ at concentrations up to $10^{-5} \mathrm{M}$ did not affect the curvature induced by $2.9 \times 10^{-7} \mathrm{M}$ of IAA, while it caused suppression at concentrations from $2 \times 10^{-6}$ to

Table 1. Effect of abscisic acid on indoleacetic acid-induced curvature in the standard Avena test

\begin{tabular}{rcc}
\hline \multirow{2}{*}{ d-ABA } & \multicolumn{2}{c}{ IAA } \\
\cline { 2 - 3 } & $2.9 \times 10^{-7} \mathrm{M}$ & $5.7 \times 10^{-7} \mathrm{M}$ \\
\hline $0 \mathrm{M}$ & $20.5 \pm 1.3$ & $26.5 \pm 1.8$ \\
$1 \times 10^{-7} \mathrm{M}$ & $19.5 \pm 1.8$ & $25.0 \pm 2.1$ \\
$2 \times 10^{-6} \mathrm{M}$ & $20.3 \pm 2.4$ & $27.0 \pm 1.9$ \\
$1 \times 10^{-6} \mathrm{M}$ & $19.5 \pm 1.4$ & $19.0 \pm 2.3$ \\
$1 \times 10^{-5} \mathrm{M}$ & $20.5 \pm 1.2$ & $18.5 \pm 1.4$ \\
\hline
\end{tabular}

\pm denotes standard error. Ten seedlings were used for each treatment.

* Department of Agricultural Chemistry, The University of Tokyo, Bunkyo-ku, Tokyo, Japan. 


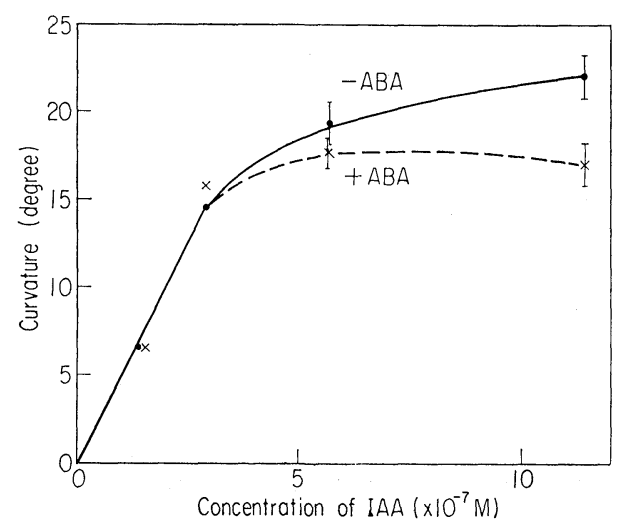

Fig. 1. Effect of abscisic acid on indoleacetic acid-induced curvature in the standard Avena test.

$+\mathrm{ABA}, 1^{-5} \mathrm{M}$ d-abscisic acid; - ABA, no addition of ABA. Bars on the curves show \pm standard errors.
$10^{-5} \mathrm{M}$ when $5.7 \times 10^{-7} \mathrm{M}$ of IAA was used (Table 1). Without the addition of IAA the inhibitor showed no effect. Similar results were obtained three times. Next the inhibitory action of $\mathrm{ABA}\left(10^{-5} \mathrm{M}\right)$ in relation to IAA concentrations was examined. As illustrated in Fig. 1 ABA was ineffective at concentrations up to $3 \times 10^{-7}$ $\mathrm{M}$ of IAA where Avena celeoptiles give a linear dose-response curve, but exerts inhibition from $5.7 \times 10^{-7}$ to $1.1 \times 10^{-6} \mathrm{M}$ of IAA, which is nearly the saturation concentration for the curvature.

These results indicate that in the Avena curvature test it is unnecessary to remove ABA from defusates or acidic ether extracts from plant tissues, and data thus far obtained by the test method without purification of samples are valid, provided that the curvature stays within the linear part of a dose-response curve.

We express our thanks to Dr. Teruko Nakamura, Laboratory of Physiology, Nippon Women's University, Tokyo, who kindly performed a part of the Avena curvature tests.

\section{References}

1) Addicott, F.T., Carns, H. R., Lyon, J. L., Smith, O.E., and McMeans, J.L., Régulateurs naturels de la croissance végétale, p 687 (Centre Nat. Reserche Scient., Paris, 1964).

2) Thomas, T.H., Wareing, P.F., and Robinson, P. M., Nature 205 : 1270 (1965).

3) Cornforth, J.W., Milborrow, B. V., and Ryback, G., Nature 210: 627 (1966).

4) Dörffling, K., Naturwissenschaften 54 : 23 (1967).

5) Isogai, Y., Okamoto, T., and Komoda,
Y., Chem. Pharm. Bull. 15: 1256 (1967).

6) Gabr, O.M.K., and Guttridge, C.G., Planta $78: 305$ (1968).

7) Hashimoto, T., Ikai, T., and Tamura, S., Planta $78: 89$ (1968).

8) Dörffling, K., and Böttger, M., Planta $80: 299$ (1968).

9) Went, F.W., and Thimann, K. V., Phytohormones (MacMillan, New York, 1937).

10) Söding, H., Die Wuchsstofflehre (Georg Thieme, Stuttgart, 1952). 